\title{
Integrated Monitoring and Assessment Framework of Regional Ecosystem under the Global Climate Change Background
}

\author{
Qiao Wang, Peng Hou, Feng Zhang, and Changzuo Wang \\ State Environmental Protection Key Laboratory of Satellite Remote Sensing, Satellite Environment Center, \\ Ministry of Environmental Protection of the People's Republic of China, Beijing 100094, China
}

Correspondence should be addressed to Peng Hou; houpcy@163.com

Received 12 February 2014; Accepted 17 March 2014; Published 13 April 2014

Academic Editor: Dong Jiang

Copyright (c) 2014 Qiao Wang et al. This is an open access article distributed under the Creative Commons Attribution License, which permits unrestricted use, distribution, and reproduction in any medium, provided the original work is properly cited.

Global changes are driving ecosystem alterations, and the effects are becoming more and more obvious. Ecosystem management clarifies the fundamental supporting functions of ecosystems for human survival and sustainable development. Integrated ecosystem monitoring and assessment has become a popular topic of ecology study. However, many scientific questions need to be addressed, including what assessment contents and methods are optimal for temporal and spatial measurements. Therefore, the development of a scientific evaluation framework that includes certain core contents and indicators is very important. This paper proposes a regional integrated ecosystem assessment framework involving comprehensive monitoring. Satellite images are the main data source for different ecosystem and ecological parameters, and these need to be supplemented with the help of surveys or field observation data. A healthy ecosystem is the basis of human survival and sustainable development, and ecological service should be taken as the core of integrated ecosystem assessment. This is decided by the spatial distribution, classification, and patterns of regional ecosystems. That is to say, ecological service, together with ecosystems distribution and pattern, ecological problem indicators, and ecological stress, needs to be integrated analyzed and evaluated.

\section{Introduction}

Global climate change is becoming one of the main driving factors of ecosystem alterations. According to the 2013 Intergovernmental Panel on Climate Change report, the global average temperature exhibits an upward linear trend from 1880 to 2012 , with a total increase of $0.85^{\circ} \mathrm{C}$. From 2003 to 2012 , the annual average temperature has increased by $0.78^{\circ} \mathrm{C}$ compared to the records from 1850 to 1900 . In the past 30 years, the warming magnitude of the surface temperature in every decade is higher than that at any time since 1850 [1]. Because of intense globalization, land resource development has significantly increased in the past 30 years, especially with regard to urban development. The double impact of climate change and human activities is driving obvious ecosystem changes in some regions [2, 3]. For sustainable human development, it is very important to comprehensively measure and assess regional ecosystem statuses over time to discover the correlation between ecosystem changes and climate and human activity intensities. It is accepted that this is an important area of study in ecology research and ecosystem management.

\section{Progress in the Integrated Monitoring and Assessment of Regional Ecosystems}

2.1. Ecosystem Management and Ecological Services. Ecosystem issues have increased in numbers and severity in recent decades, such as reductions in ecosystem biodiversity [4]. Scientists and managers have begun to pay more attention to the ecosystem and correlations between its different elements. Such knowledge can provide guidance on how to maintain ecosystem function and support the sustainable development of humankind. This requires the timely assessment and monitoring of ecosystems. 
The Research Committee of the Plant and Animal Population of American Ecology Society played an active role in the initial development of ecosystem management. In 1932, the committee considered that American comprehensive nature security system should include natural ecosystem protection [5]. In 1950, the Commission put forward a proposal to perform natural safety investigations [6]. Subsequently, some environment policy researchers had begun to advocate developing public land management policies based on ecosystem management [7]. In the late 1980s, growing numbers of scientists and managers identified and supported the opinion that ecosystem management is an effective measure to protect ecology. The first monograph about ecosystem management appeared in 1988, titled "Ecosystem Management for Parks and Wilderness," and was written by Jim Agee and Darryll Johnson based on the result of a 1987 workshop. In session, a group of managers, scientists, and planners concerned with the future of parks, wilderness areas, and other nature reserves discussed a framework for how to manage these areas most effectively, and the focus was cooperative ecosystem management. This book presented a theoretical framework that included both general goals and processes for achieving these goals [8]. Ecosystem management was summarized by Edward Grumbine in 1994 as ten themes according to papers and books published in that period [9], and ten dominant themes are, respectively, hierarchical context, ecological boundaries, ecological integrity, data collection, monitoring, adaptive management, interagency cooperation, organizational change, humans embedded in nature, and values.

After 2000, the concept of integrated ecosystem management was introduced into the field of ecology research and ecosystem management. In the fifth conference of the "Biodiversity Convention," ecosystem approach is regarded as a strategy for the integrated management of land, water, and living resources that promotes conservation and sustainable use in an equitable way, and the application of the ecosystem approach will help to reach a balance of the three objectives of the convention: conservation, sustainable use, and the fair and equitable sharing of the benefits arising out of the utilization of genetic resources [10]. Based on this viewpoint, twelve principles of integrated ecosystem management were proposed in detail [10]. The 2010 China International Cooperation Association Annual Meeting selected ecosystem management and green development as the common theme, and the meeting focused on issues related to ecology and economy, environmental protection and green development, and promoting the development of China's ecosystem management [11]. Some regional ecology management and ecological restoration problems, such as prevention and restoration of land degradation, began to be addressed via integrated ecosystem management [12].

Under ecosystem integrated management, more attention is paid to the ecosystem as a whole rather than dividing the problems and focusing on specific elements. Separate studies of ecosystem elements are helpful for better understanding complex ecosystem relationships and recognizing the factors that affect ecological service [4]. With the development of ecosystem management, knowledge about how ecosystems support social development has increased, the concept of ecosystem services had been proposed, and it has become a popular topic of ecosystem management research. Ecosystem service refers to a variety of incomes received directly or indirectly from ecosystems by human beings [13]. In 1997, Daily published a groundbreaking book about ecosystem service, which he named as "natural service." In it, he detailed the definition, theory, and other central knowledge about ecosystem services [14]. In the same year, Daily and Costanza's two important publications on ecosystem service became milestones in the progress of the concept of ecosystem service. Daily outlined the main types of ecosystem services, the major threat factors for maintaining ecosystem services, and discussed how to evaluate these services [13]. Costanza initially estimated the total value of the global ecosystem at about $\$ 30$ trillion per year [15]. In 2001, the United Nations launched the Millennium Ecosystem Assessment project, another landmark of ecosystem service, which tremendously promoted the worldwide development of ecosystem service.

\subsection{Classical Cases of Integrated Assessment. Lots of classical} cases of integrated assessment of ecosystems have been implemented in recent periods, listed in the Table 1 . The Millennium Ecosystem Assessment project uses ecosystem service, mainly including supply, regulating, supporting, and cultural services, as the core of the ecological assessment framework. It comprehensively considers the ecosystem on national, regional, and global scales and predicts its possible future statuses in different scenarios. Then, the relationship between ecosystem changes and human wellbeing was analyzed to determine how ecosystem changes were affected by human activities in the past and how the ecosystem will affect the human wellbeing in the future. This project had an important impact on the international community and many governments. The Millennium Ecosystem Assessment project also promoted the development of ecology ecosystem service, confirmed the strong correlation between ecosystems and human wellbeing, and improved the management level of the ecosystem [16-18].

On a national scale, the US has performed two national ecosystem assessments and released the reports in 2002 and 2008. The national assessment divided ecosystems into six types, including farmland, forest, grassland and shrubland, freshwater, urban, and coastal and marine. The assessment framework and core aspects were distribution and pattern, chemical and physical characteristics, biological components, substance supply, and service of ecosystem. Changes and status of national land, water, and biology resources were also analyzed, and a total of 108 key assessment indicators were examined. These reports objectively reflected the real process of ecological change in the national ecosystem [19]. In the UK, the national ecosystem was divided into mountainmoorland-heath, seminatural grasslands, enclosed farmland, forests, open freshwater waters, wetlands-floodplains, urban, coastal, marine, and so on, for a total of 8 first-class and 32 second-class ecosystems. The UK assessment framework and core contents were ecosystem service, material supply, driving force of ecosystem change, and human wellbeing. 
TABLE 1: Comparative list of classical cases of integrated assessment.

\begin{tabular}{|c|c|c|c|}
\hline Case & Scale & Ecosystem type & Framework and content \\
\hline $\begin{array}{l}\text { Millennium } \\
\text { ecosystem } \\
\text { assessment }\end{array}$ & Global & $\begin{array}{l}\text { Ecosystems were divided into } 13 \text { types: Mediterranean } \\
\text { forests, woodlands, and scrub; temperate forest steppe } \\
\text { and woodland; temperate broadleaf and mixed forests; } \\
\text { tropical and subtropical dry broadleaf forests; flooded } \\
\text { grasslands and savannas; tropical and subtropical } \\
\text { grasslands, savannas, and shrublands; tropical and } \\
\text { subtropical coniferous forests; deserts; montane } \\
\text { grasslands and shrublands; tropical and subtropical } \\
\text { moist broadleaf forests; temperate coniferous forests; } \\
\text { boreal forests; tundra. }\end{array}$ & $\begin{array}{l}\text { Assessment focused on the linkages between } \\
\text { ecosystems and human well-being and, in } \\
\text { particular, on ecosystem services, examined } \\
\text { the ecosystem changes affecting human } \\
\text { wellbeing, and discovered the critical factors } \\
\text { causing ecosystem changes, and put forward } \\
\text { the measures managing ecosystems } \\
\text { sustainably. }\end{array}$ \\
\hline $\begin{array}{l}\text { National } \\
\text { ecosystem } \\
\text { assessment } \\
\text { in the US }\end{array}$ & National & $\begin{array}{l}\text { Ecosystems were divided into six types: farmland, } \\
\text { forests, grassland and shrublands, freshwater, urban, } \\
\text { and coastal and marine. }\end{array}$ & $\begin{array}{l}\text { Assessment focused on the distribution and } \\
\text { pattern, chemical and physical } \\
\text { characteristics, biological components, } \\
\text { substance supply, and ecosystem service. }\end{array}$ \\
\hline $\begin{array}{l}\text { National } \\
\text { ecosystem } \\
\text { assessment } \\
\text { in the UK }\end{array}$ & National & $\begin{array}{l}\text { Ecosystems were divided into eight types: forests, } \\
\text { coastal, marine, mountain-moorland-heath, } \\
\text { seminatural grasslands, enclosed farmland, open } \\
\text { freshwater waters, urban, and wetlands-floodplains. }\end{array}$ & $\begin{array}{l}\text { Assessment focused on the ecosystem } \\
\text { service, material supply, driving force of } \\
\text { ecosystem change, and human wellbeing. }\end{array}$ \\
\hline $\begin{array}{l}\text { National } \\
\text { ecosystem } \\
\text { assessment } \\
\text { in China }\end{array}$ & National & $\begin{array}{l}\text { Ecosystems were divided into eight types: forests, } \\
\text { shrublands, wetlands, grassland, farmland, urban, } \\
\text { desert, glacier and bare land. }\end{array}$ & $\begin{array}{l}\text { Assessment focused on the ecosystem } \\
\text { distribution and pattern, service, quality, } \\
\text { problems, driving factors. }\end{array}$ \\
\hline
\end{tabular}

Evaluations on the national terrestrial, freshwater, and marine ecological status and its changes on national and regional scales have been performed [20]. In addition, with the implementation of the Millennium Ecosystem Assessment, many European countries also carried out national assessments of the state of ecosystems, including Spain, Portugal, Poland, and other countries [21].

In contrast with the national assessments of ecosystems in developed countries, China first launched a comprehensive assessment of national ecosystems in 2000 and completed the first comprehensive assessment of the ecological status of the whole country. Now the second has been completed, and the assessment report is currently being drafted. This second assessment took full advantage of satellite remote sensing in combination with traditional field survey methods, and the national ecosystem was fully assessed at national, regional, and province scales. The evaluation framework and core content included distribution and pattern, quality, service and function, problems, and ecosystem stress. A lot of key assessment indicators were analyzed, and basic ecosystem information from satellite images has been collected in the past decade. This evaluation revealed the spatial and temporal variation of the ecosystem during this time period, and recognized the effect of protective measures and the influences of social and economic improvement. Because development is moving quickly in China, the relationship between protection and development had received more attention in some regions. Five protected regions and five development regions were selected to better understand this relationship. Compared with the first study, when distribution and ecosystem patterns were the focus, the second study examined ecological service and ecosystem distribution.

\section{Key Science Issues Regarding Integrated Monitoring and Regional Ecosystem Assessment}

3.1. How to Ascertain the Optimal Assessment Contents and Methods? Ecosystems consist of nonbiological environments, producers, consumers, and decomposers, meaning that they are open, pluralistic, dynamic, hierarchical, self-sustaining, complex systems. Multiple assessments that examine the atmosphere, hydrosphere and biosphere, and lithosphere are necessary to understand such systems. With the improvements of cognizing the relationship between ecosystems and human wellbeing, ecosystem services that support the sustainable development of society have become the core of integrated ecosystem assessments. Ecosystem service is one of the most popular topics of study in ecology and is receiving more attention from governments and organizations. The United Nations Millennium Ecosystem Assessment report found that 15 of 24 global ecosystem services are being degraded, resulting in significant impacts on human wellbeing $[16,17]$. Many ecological problems are due to the destruction and degradation of the ecosystem [22]. However, many scientific questions need to be addressed, such as definition, classification, calculation method, and assessment indicators and criteria. However, ensuring that criteria are appropriate is very difficult because factors such as economy levels, society awareness, public diathesis, and consumption habits vary among different regions.

Notwithstanding different definitions of ecosystem service, all of them consider humankind as the beneficial main body. Ecological service classification is difficult because the ambiguities of ecosystem services and benefits result in different classifications of ecological service. Daily generalized 
nine types of ecosystem services, including production of ecosystem goods, biodiversity generation and maintenance, climate and life, mitigation of floods and droughts, services supplied by soil, pollination, natural pest control services, seed dispersal, and aesthetic beauty and intellectual and spiritual stimulation [13]. Costanza thought that ecological service included 17 aspects [15]. According to the Millennium Ecosystem Assessment report, ecological services include provisioning, regulating, cultural, and supporting services [16]. Besides these issues, assessment methods lack supporting scientific research and long-term observation data. As such, region assessments often directly apply the evaluation model or model parameters or indicators from other region or research cases, which can lead to inaccurate conclusions. Unique characteristics of the ecosystem must be taken into account to arrive at regional evaluation conclusions. Therefore, it is important to optimize evaluation model parameters and indicators according to the regional nature features and assessment theme.

Due to the complex and interlaced correlations of ecosystems with other nature elements and human activities, it is difficult to quantitatively analyze the driving factors of change. At present, the contribution of different factors is recognized with the help of qualitative methods. The few cases of quantitative analysis that have been published are based on the correlation model, but this model and analysis are lacking in a principle foundation.

\subsection{How to Ascertain Optimal Spatial and Temporal Scales?} Ascertaining optimal scales is a foundation of integrated ecological system assessment and directly influences assessment conclusions. It is well known that the ecosystem is an organic whole in a certain spatial area, consisting of organisms and their surroundings, and these components are connected with each other via the exchange of material and energy flow within the system [23]. An ecosystem is a very important level in ecological organization and has comprehensive characteristics of regional, landscape, and population ecology. Ecosystem structure, processes, and function are interacting and interdependent. Structure and process determine ecosystem function; inversely, function influences ecosystem structure and process. Changing scales affect the structure and process of the ecosystem, which affects the methods and conclusions of ecological research and evaluations. That is to say, differences in scale result in different assessment conclusions [24]. For example, the assessment conclusion of the ecosystem service of the Three-River Headwaters region in China was different on the regional and national scales. Because this region is the source of the Yangtze, Yellow, and Lancang Rivers, water conservation and hydrological regulation is the most important ecological service on a national level. However, on the local scale, people are nomadic and there is good pasture; therefore, supplying service is the most important factor.

Ecosystem processes can only be properly understood when the inherent heterogeneity of ecosystems and organisms reacting to this heterogeneity are recognized [25]. The inherent heterogeneity of ecosystems is decided by the scale. The bigger the scale, the more obvious the inherent heterogeneity. For example, to assess spatial differences of the hydrological regulation abilities of deciduous and coniferous forests on a large scale, it is sufficient to examine vegetation type group differences (e.g., deciduous and coniferous forests). On a moderate scale, there is a need to further distinguish the different hydrological regulation ability resulting from different vegetation types and tree species in the same vegetation type group (e.g., cedar, mason pine). On a small scale, even tree age should be considered. On a temporal scale, heterogeneity is an important characteristic. The wider the time span, the smaller the sampling interval; the more obvious the change trend, the narrower the time span; the smaller the sampling interval, the more unobvious change trend. That is to say, for the same phenomena, it is spatialhomogeneity on a large scale and spatialheterogeneity on a small scale.

\section{Framework of Comprehensive Ecosystem Monitoring and Assessment}

4.1. General Framework and Core Contents. For integrated ecosystem assessment, it is very important to employ a scientific and applicable framework. In general, regional integrated assessment includes comprehensive monitoring and an integrated assessment. Therefore, the general framework of integrated ecosystem monitoring and assessment is shown in Figure 1. This framework pays more attention to the single ecosystem changes and the intertransform of different ecosystems and focuses on the results of these changes, such as change of ecological services, does not take the change of individuals in the ecosystem as the emphasis. It is adaptive to the regional assessments of global, subglobal, continental, national, state or provincial spatial scales or lager drainage area.

Comprehensive monitoring is the fundamental component, and exact model and data precision determine the reliability of the assessment conclusion. Satellite imaging is a powerful tool for monitoring macroecology; it can be used to periodically scan the same regions and synchronize recording information. Thus, it can be used to assess the distributions of different ecosystems and determine the statuses of main ecological parameters, such as vegetation coverage, biomass, and leaf area index of vegetation. Of course, such data must be supplemented by survey or observation data with temporary or permanent field stations. For the sake of ascertaining model parameters, some experiences and parameter data need to be gathered from published books and papers. Because of the inseparable relationship between ecosystems and human beings, data about social, economic, meteorological, hydrological, agricultural, and land and resource exploitation also need to be collected.

Because a healthy ecosystem is the basis of human survival and sustainable development, ecological service must be at the core of integrated ecosystem assessment. Ecological service is decided by the quantity and quality of a regional ecosystem. According to this, regional ecosystem spatial distribution, classification, and pattern need to be analyzed. The same kinds of ecosystems with different spatial patterns result 


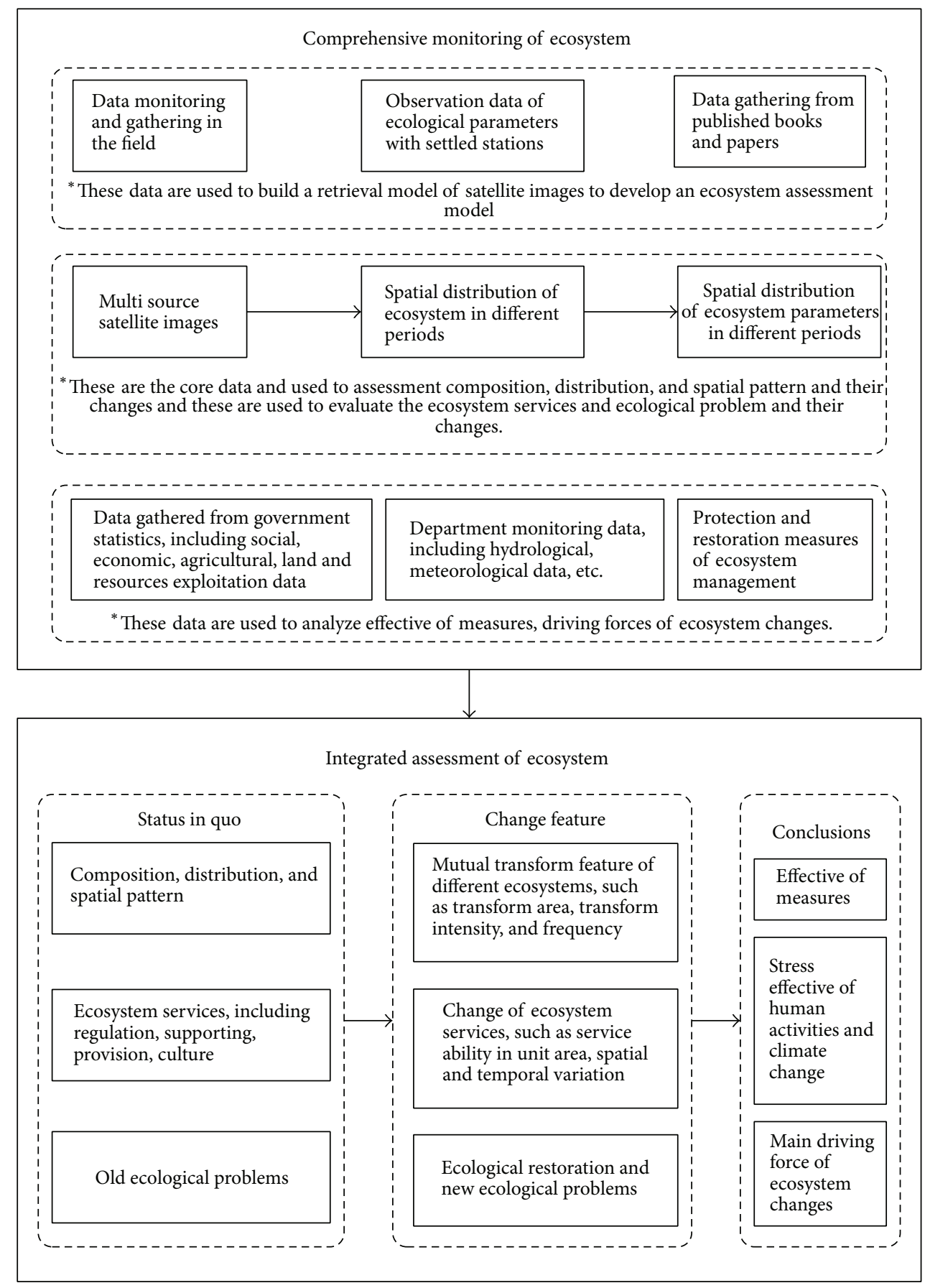

FiguRE 1: General framework of integrated ecosystem monitoring and assessment.

in different ecological processes and functions. Analyzing ecosystem features is important. Firstly, the mutual transform features of different ecosystems are recognized by calculating the transform quantity, intensity, and frequency. The core of ecological change assessment is investigating changes in ecosystem service, including regulation, provision, support, and culture. These assessments can be done with the help of indicators, such as service ability in the unit area and spatial and temporal variations. Notwithstanding, ecosystem change is a basic phenomenon of ecological succession; the direction of ecosystem change from superior to inferior is not consistent with public requirements and is considered to be indicative of ecological degradation. The ultimate goal of integrated ecosystem assessment is to identify factors driving change, including the positive changes or restoration with the help of management measures, negative change or degradation under the stress of exploitation and construction activities, and the impacts of climate change. The recognition of the driving factors of ecological change is a precondition to design effective measures to protect and utilize nature. 
4.2. Indicators of Monitoring and Assessment. According to the core contents of monitoring and assessment, indicators are divided into four groups: distribution and pattern indicators, ecological service indicators, ecological problem indicators, and stress indicators.

Distribution and pattern indicators are used to assess the spatial and temporal distributions and patterns and their changes within regional ecosystems. Ecosystem distribution can be depicted on a spatial distribution by two indicators, namely, area and percentage. (1) Ecosystem patterns can be depicted by landscape pattern indexes, such as number of patches, mean patch area, contagion, Shannon's diversity index, and patch richness. Their ecological meaning and calculation models are detailed and applied in some articles and cases [26-28]. (2) Changes in ecosystem can be shown with two indicators: transform area and percentages between different ecosystems and total transform area and the percentage of all ecosystems. As one of the statistic approaches, transition matrix are usually used, this method can distinctly list the transition area and percentage from one type to another type [28].

Ecological service indicators are mainly used to assess regulation services and their changes. Different services are evaluated by different indicators. (1) Water conservation service is the ability of the ecosystem to conserve water and can be calculated by three indicators: (1) interception ability of rainfall by vegetation canopies and conserving rainfall ability by (2) vegetation litters and (3) topsoil. Interception ability can be obtained by multiplying canopy interception rate and rainfall and forest acreage, as the key parameter, and canopy interception rate of the different forest subplot is observed in the field. Conserving rainfall ability of vegetation litters and topsoil can be estimated with water-holding ability per litter or topsoil and their total volume. This method is carried out in some cases [29]. (2) Soil conservation service is topsoil service, when the surface layer is eroded by water and wind, and it can be calculated by two indicators: the ability of soil and water conservation and the ability of sand fixation. Soil conservation is generally defined as the ability to prevent soil erosion caused by water eroding, widely evaluated with Universal Soil Loss Equation (USLE), and describes soil erosion processes, and is used by United States government agencies to measure water erosion [30-32]. Sand fixation is the ability to prevent soil erosion caused by wind eroding, can be estimated with the Revised Wind Erosion Equation (RWEQ), and has a high accuracy, taking into account the weather, soil, plants, plots, farming and irrigation factor, and so on $[33,34]$. (3) Hydrological regulation service is the ability to regulate floodwater and can be calculated by two indicators: the maximum of recharge water by rivers, lakes, and reservoir and decreasing flow speed by the land surface. About hydrological regulation service of the rivers, lakes, and reservoir, maximum of recharge water is estimated by the maximum storage capacity minus the existing water volume. About that of the other ecosystems, hydrological regulation service mainly results from decreasing the flow speed by the land surface, such as grass, forest, and crop; this can be estimated with Soil Conservation Service (SCS) model [35] or Soil and Water Assessment Tool (SWAT) model [36]. (4) Carbon dioxide gas regulation service is the ability of abstracting, fixating, and releasing carbon, and it can be calculated by quantifying carbon fixation levels. In ecosystem, fixating carbon mainly resulted from three parts: aboveground biomass, belowground biomass, and soil. Carbon fixed by aboveground biomass can be estimated with satellite images [37-39]. According to the aboveground biomass and root-top ratio, belowground biomass and its ability can be calculated. Soil carbon is mainly based on the average soil depth, average bulk density, and average carbon density [40]. In a larger region, soil carbon can estimated from vegetation type, soil type, and other key factors with the help of remote sensing [41].

Ecological problem indicators are mainly used to assess ecosystem degradation intensity and area. (1) Forest degradation can be calculated by three indicators: change of predominant species, change of species construction, and change of biomass. (2) Grass degradation can also be calculated by three indicators: change of predominant species, change of species construction, and change of vegetation coverage. (3) Wetland degradation can be calculated by five indicators: change of indication species, change of species construction, changes in water volume and quality, humidity of the surface layer, and change of area. All these indicators, most of them need to be measured in the field. However, vegetation coverage is usually retrieved from Normal Difference Vegetation Index (NDVI) data, and humidity of the surface layer can be obtained from the radar data scatter features [42].

Stress indicators are mainly used to assess pressure on ecosystems due to natural conditions and human activities, and this information is used to identify reasons underlying ecosystem changes. They can be divided into two groups: nature stress and human activity stress. (1) Nature stress can be analyzed by climate change, and the main indicators are temperature, precipitation, net radiation from the sun, and climate change driving ecosystem change usually analyzed with the statistical correlation and Empirical Orthogonal Functions (EOF) methods [3, 43, 44]. (2) Changes in human activity intensity and distribution. The main indicators of human activity are economic development intensity and impermeable layer expansion. According to the analysis cell, change of centroid location is used to find the relationship between change of economic product population and ecosystem change [45]. Expansion of land exploitation, including impermeable layer expansion and mine resources exploiture, resulting into the change of ecosystem can be analyzed with transition matrix method.

\section{Conclusions}

Global change, including climate warming and water resource shortages, is driving ecosystem changes, and the effects are becoming more obvious. To better protect and manage ecosystems, the concept of ecosystem management and ecosystem service was proposed to ensure human survival and sustainable development. Integrated ecosystem monitoring and assessment has become a focus of ecology that demands increasing international attention. Many 
researchers and governments actively carry out ecosystem assessment cases on different scales. Determining the scientific and rational evaluation framework is the key step, which influences the precision and reliability of conclusions from ecosystem studies. The framework includes assessment scope, contents, indicators, and technical methods.

A regional integrated ecosystem assessment framework is proposed based on the literature and study practices. Regional integrated assessment can be carried out with comprehensive monitoring and integrated assessment. Comprehensive monitoring is fundamental. Satellite images are used as the main data source, and these images are supplemented by surveys or field data from temporary or permanent stations. Other approaches, including collecting statistical data and gathering data from documents, can further supplement satellite imagery and field data. With integrated assessment, ecosystem status, change, and its driving factors are the main contents, and ecological services are at the core. Ecosystem spatial distribution, classification, and their regional patterns need to be analyzed to make informed decisions with regard to ecosystem services. According to the core monitoring and assessment contents, indicators can be divided into four groups: distribution and pattern indicators, ecological service indicators, ecological problem indicators, and stress indicators in turns.

\section{Conflict of Interests}

The authors declare that there is no conflict of interests regarding the publication of this paper.

\section{Acknowledgments}

This paper benefitted from the assessment framework of the "National ecological survey and assessment of environmental change from 2000 to 2010." The authors express their heartfelt thanks to the group of scientists, managers, and colleagues involved in the project, especially Zhiyun Ouyang and Hua Zheng, and research team members of Professor Ouyang at the Research Center for Eco-Environmental Sciences, Chinese Academy of Sciences.

\section{References}

[1] Intergovernmental Panel on Climate Change, Climate Change 2013: The Physical Science Basis, 2013, http://www.climatechange2013.org.

[2] B. H. Braswell, D. S. Schimel, E. Linder, and B. Moore III, "The response of global terrestrial ecosystems to interannual temperature variability," Science, vol. 278, no. 5339, pp. 870-872, 1997.

[3] P. Hou, Q. Wang, G. Z. Cao, C. Z. Wang, Z. M. Zhan, and B. F. Yang, "Sensitivity analyses of different vegetations responding to climate change in inland river basin of China," Journal of Geographical Sciences, vol. 22, pp. 387-406, 2012.

[4] E. Maltby, M. Holdgate, M. Acreman, and A. Weir, Ecosystem Management: Question for Science and Society, Royal Holloway Institute for Environmental Research, London, UK, 1999.
[5] V. E. Shelford, "Ecological society of America: a nature sanctuary plan unanimously adopted by the society, December 28 , 1932," Ecology, vol. 14, pp. 240-245, 1993.

[6] S. C. Kendeigh, H. I. Baldwin, V. H. Calahane et al., "Nature sanctuaries in the United States and Canada: a preliminary inventory," The Living Wilderness, vol. 15, no. 35, pp. 1-45, 1951.

[7] L. Caldwell, "The ecosystem as a criterion for public land policy," Natural Resources Journal, vol. 10, no. 2, pp. 203-221, 1970.

[8] J. K. Agee and D. R. Johnson, Ecosystem Management for Parks and Wilderness, University of Washington Press, 1988.

[9] R. E. Grumbine, "What is ecosystem management?" Conservation Biology, vol. 8, no. 1, pp. 27-38, 1994.

[10] The Secretariat of the Convention on Biological Diversity, Decisions Adopted by the Conference of the Parties to the Convention on Biological Diversity at Its Fifth Meeting: Ecosystem Approach, 2000.

[11] China Council for International Cooperation on Environment and Development, "Annual policy report 2010: ecosystem management and green development," Annual Report, China Environment Science Press, 2011.

[12] Z. H. Jiang, Proceedings of the International Workshop: Integrated Ecosystem Management, China Forestry Publishing House, 2006.

[13] G. C. Daily, S. Alexander, P. R. Ehrlich et al., "Ecosystem services: benefits supplied to human societies by natural ecosystems," Issues in Ecology, vol. 2, pp. 1-18, 1997.

[14] G. C. Daily, Nature's Services: Societal Dependence on Natural ecosystems, Island Press, 1997.

[15] R. Costanza, R. D’Arge, R. De Groot et al., "The value of the world's ecosystem services and natural capital," Nature, vol. 387, no. 6630, pp. 253-260, 1997.

[16] Millennium Ecosystem Assessment, Ecosystems and Human Well-Being: A Framework for Assessment, Island Press, 2003.

[17] Millennium Ecosystem Assessment, Ecosystems and Human Well-Being: Synthesis, Island Press, 2005.

[18] S. D. Zhao and Y. M. Zhang, "Ecosystems and human wellbeing: the achievements, contributions and prospects of the Millennium Ecosystem Assessment," Advances in Earth Science, vol. 21, no. 9, pp. 896-902, 2006.

[19] H. The John Heinz III center for science, economics, and the environment, The State of the National's Ecosystems 2008: measuring the lands, waters and living resources of the United States, Island Press, 2008.

[20] U. K. National Ecosystem Assessment, The UK National Ecosystem Assessment: Synthesis of the Key Findings, UNEP-WCMC, Cambridge, UK, 2011, http://uknea.unep-wcmc.org.

[21] P. Hou, "Improving the China periodical comprehensive assessment mechanism of ecosystem condition based on Chinese and foreign experience," Environment Protect, vol. 41, no. 23, pp. 7173, 2013.

[22] B. J. Fu, G. Y. Zhou, Y. F. Bai et al., "The main terrestrial ecosystem service and ecological security in China," Advance in Earth Science, vol. 24, no. 6, pp. 571-576, 2009.

[23] G. I. Agren and F. O. Andersson, Terrestrial Ecosystem Ecology: Principles and Application, Cambridge University Press, Cambridge, UK, 2012.

[24] J. A. Wiens, "Spatial scaling in ecology," Functional Ecology, vol. 3, no. 4, pp. 385-397, 1989.

[25] L. Fahrig, Theoretical Population Biology: Relative Importance of Spatial and Temporal Scales in a Patchy Environment, Academic Press, 1992. 
[26] M. G. Turner, R. V. O’Neill, R. H. Gardner, and B. T. Milne, "Effects of changing spatial scale on the analysis of landscape pattern," Landscape Ecology, vol. 3, no. 3-4, pp. 153-162, 1989.

[27] J. Wu, Landscape Ecology-Pattern, Process, Scale and Hierarchy, China Higher Education Press, 2nd edition, 2007.

[28] P. Hou, C. Z. Wang, W. G. Jiang, and Y. W. Zhao, "Ecological effective of land-use and land-cover change in watershed scope," Geographical Research, vol. 30, no. 11, pp. 2092-2098, 2011.

[29] Z. Biao, L. Wenhua, X. Gaodi, and X. Yu, "Water conservation of forest ecosystem in Beijing and its value," Ecological Economics, vol. 69, no. 7, pp. 1416-1426, 2010.

[30] K. G. Renard, G. R. Foster, G. A. Weesies, D. K. McCool, and D. C. Yoder, "Predicting soil erosion by water: a guide to conservation planning with the revised universal soil loss equation (RUSLE)," in Agriculture Handbook, U.S. Department of Agriculture, 1997.

[31] W. H. Wischmeier and D. D. Smith, "A universal soil-loss equation to guide conservation farm planning," Transactions of 7th International Congress of Soil Science, vol. 1, pp. 418-425, 1960.

[32] N. Hudson, Field Measurement of Soil Erosion and Runoff, Food and Agriculture Organization of the United Nations, 1993.

[33] D. W. Fryrear, A. Saleh, J. D. Bilbro, H. M. Schomberg, J. E. Stout, and T. M. Zobeck, "Revised wind erosion equation (RWEQ)," Technical Bulletin, Wind Erosion and Water Conservation Research University and the USDA-ARS, Southern Plains Area Cropping Systems Research Laboratory, 1998.

[34] D. W. Fryrear, P. L. Sutherland, G. Davis, G. Hardess, and M. Dollar, "Wind erosion estimates with RWEQ and WEQ," in Proceedings of the 10th International Soil Conservations Organization, Sustaining the Global Farm, Purdue University and the USDA-ARS National Soil Erosion Research Laboratory, May 1999.

[35] P. Hou, W. G. Jiang, Z. L. Chen, and A. M. Luo, "Hydrological recharge effect of precipitation on Dongting Lake Wetland," Geographical Research, vol. 28, no. 2, pp. 371-378, 2009.

[36] Y. Zhang, J. Xia, Q. Shao, and X. Zhai, "Water quantity and quality simulation by improved SWAT in highly regulated Huai River Basin of China," Stochastic Environmental Research and Risk Assessment, vol. 27, no. 1, pp. 11-27, 2013.

[37] J. Estornell, L. A. Ruiz, B. Velázquez-Martí, and A. FernándezSarría, "Estimation of shrub biomass by airborne LiDAR data in small forest stands," Forest Ecology and Management, vol. 262, no. 9, pp. 1697-1703, 2011.

[38] R. Nelson, W. Krabill, and J. Tonelli, "Estimating forest biomass and volume using airborne laser data," Remote Sensing of Environment, vol. 24, no. 2, pp. 247-267, 1988.

[39] Y. P. Yang, G. Z. Cao, P. Hou, W. G. Jiang, Y. H. Chen, and J. $\mathrm{Li}$, "Monitoring and evaluation for climate regulation service of urban wetlands with remote sensing," Geographical Research, vol. 32, no. 1, pp. 73-80, 2013.

[40] E. Gorham, "Northern peatlands: role in the carbon cycle and probable responses to climatic warming," Ecological Applications, vol. 1, no. 2, pp. 182-195, 1991.

[41] S. Wang, H. Tian, J. Liu, and S. Pan, "Pattern and change of soil organic carbon storage in China: 1960s-1980s," Tellus B: Chemical and Physical Meteorology, vol. 55, no. 2, pp. 416-427, 2003.

[42] W. X. Liu, X. L. Liu, J. Wang, and W. H. Zeng, "Remote sensing retrieval of soil moisture using ENVISAT-ASAR and MODIS images in vegetated areas of human," Agricultural Research in the Arid Areas, vol. 26, no. 3, pp. 39-43, 2008.
[43] W. Jiang, P. Hou, X. Zhu, G. Cao, X. Liu, and R. Cao, "Analysis of vegetation response to rainfall with satellite images in Dongting Lake," Journal of Geographical Sciences, vol. 21, no. 1, pp. 135-149, 2011.

[44] P. Hou, W. M. Shen, Q. Wang, W. G. Jang, Y. H. Chen, and J. Li, "Quantitative analysis of driving factors for wetland degradation based on hydrology balance," Acta Ecologica Sinica, vol. 34, no. 3, pp. 660-666, 2014.

[45] X. Lei, B. Yang, W. G. Jiang, Y. P. Yang, C. Kuenzer, and Q. Chen, "Vegetation pattern changes and their influencing factors in the East Dongting Lake Wetland," Geographical Research, vol. 31, no. 3, pp. 461-470, 2012. 

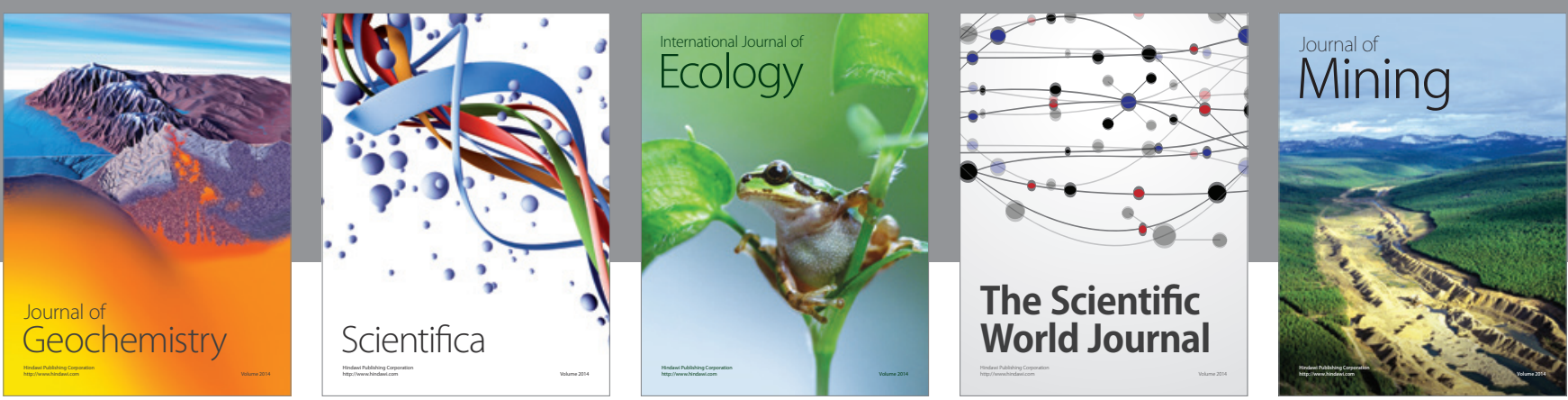

The Scientific World Journal
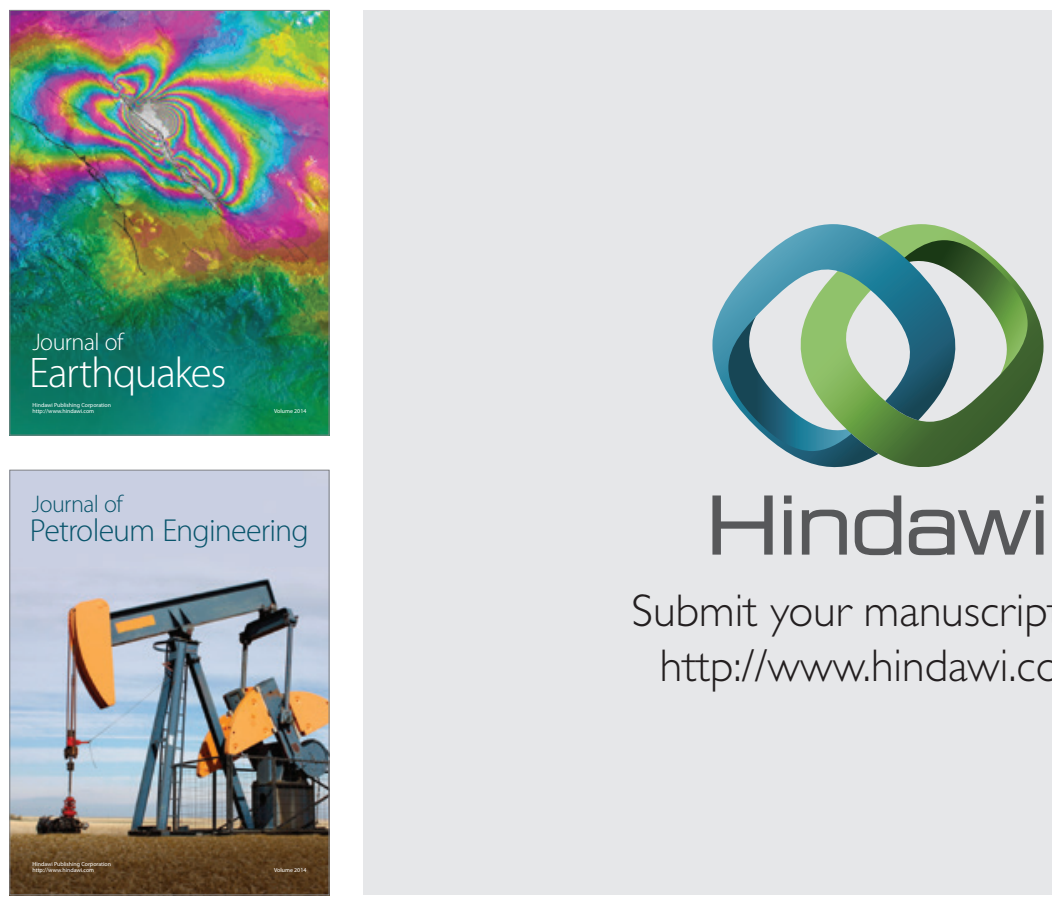

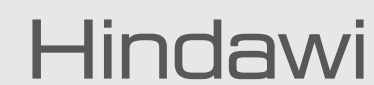

Submit your manuscripts at

http://www.hindawi.com

